\title{
The Impact of Quality of Online Banking on Customer Commitment
}

\author{
Chakib HAMADI \\ University of Marrakesh, Marrakesh, Morocco
}

\begin{abstract}
This article demonstrates the existence of a causal relationship between perceived quality, satisfaction and commitment in the context of online banking. The results show that the perceived quality heavily influences the commitment of customers and that this effect is direct and not mediated by satisfaction.
\end{abstract}

Keywords: perceived quality, satisfaction, commitment, Internet banking.

\section{Introduction}

The Internet banking has opened a new avenue to exploit to make a distinction between banks and deliver a superior service compared to competitors. It involves the use of the Internet by consumers to get in touch with their banks and check their accounts and carry out banking transactions. The migration to Internet banking has greatly influenced the distribution policies of banks and the mode of interaction with the banking and service experience for consumers. Thus, retention and attraction of consumers are largely determined by the quality of services delivered.

The aim of this research is to study the impact of the quality of online banking services on customers intention to revisit the banking site and to maintain a lasting relationship with it. It will also verify the mediating role of satisfaction in that relationship. It is twofold. From a theoretical viewpoint, this research enriched the few studies that have explored the concept of perceived quality of online services. From a managerial point of view, it points to the bankers the importance of promoting satisfaction factors which could produce favorable behavioral intentions among customers.

This article is organized as follows: initially, the conceptual framework is exposed, then the methodology will be presented and finally the results and the contributions and voices of future research will be shown and discussed.

\section{I- Electronic quality}

Several studies have identified dimensions of online perceived quality. The applications in the field of Internet banking are partial and very rare. This is an area of research where one is concerned primarily with the security of the site. Thus, it seems rewarding to refer mainly to studies on the identification of dimensions for evaluating the online quality. Work on electronic service quality and satisfaction online (Wolfinbarger and Gilly,

2003, Srinivasan andal., 2002, Yoo and Donthu, 2001; Novak and al., 2000, Liu and Arnett, 2000; Szymanski and Hise, 2000), work on technologies of self-service (Bateson, 1985; Dabholkar, 1996 and Meuter and al., 2000), work on Internet banking (Jun and Cai, 2001; Aladwani 2001, Liao and Cheung , 2002; Jayawardhena, 2004) provide information on the dimensions most often cited in literature and which will form the basis for assessing the perceived quality of Internet banking (see Annex 1).

The perceived quality of Internet banking referred to the theoretical field of electronic quality. It has been designed differently and has

Copyright (C) 2010 Chakib HAMADI. This is an open access article distributed under the Creative Commons Attribution License unported 3.0, which permits unrestricted use, distribution, and reproduction in any medium, provided that original work is properly cited. Author contact: Chakib HAMADI, e-mail: hamadi_chakib@yahoo.fr 
been extensively tested at merchant sites. According to Zeithaml and al. (2000), electronic service quality components include pre and post-service experience with the website. It is evaluating the effectiveness and efficiency by which a website facilitates shopping; purchase and delivery of products or services. Santos (2003) defines it as "all the evaluations and judgments of consumers about the degree of excellence of electronic services.

\section{II- Commitment}

Boulaire and Mathieu (2000, p.1) define the commitment in respect of a site as "a psychological state that the user maintains with a website, statement characterizing his relationship with the site having implications for the maintenance of it or not, corresponding to an affective or (and) calculated commitment of the surfer to the site". The authors retain two dimensions: affective commitment and calculated commitment. The affective commitment to a site can result from experiences on the Internet and through a site and the immediate emotional gratification that it brings. Two sub-dimensions characterize affective commitment: the symbolic dimension and the hedonistic dimension of the site. Commitment calculated, meanwhile, refers to the cognitive process by monitoring the surfer to reach the outcome, the decision to continue his relationship with a site. In this perspective, the calculated commitment is characterized by three sub-dimensions: the absence of alternatives, satisfaction with the chosen site and then switching costs.

The authors therefore insist on two forms of commitment: a commitment based on emotional attachment that develops in the relationship between the surfers and the site that expressing the emotions felt during the browsing experience. The emotional dimension can give a good chance for cyberconsumer to issue the same behavior (purchase, revisits the site) and it's more important than calculated dimension which is depending on the number of alternatives or switching costs.

Park and Kim (2003) and Chiou (2004) note that on Internet, commitment is often seen as the intention to revisit the site, intention to buy on the site or intention to recommend the site. In this research, commitment to the site will be considered as an overall assessment resulting from satisfaction. It is defined as "intention to maintain a valued relationship with the site (Park and Kim, 2003).

\section{III- Satisfaction}

Satisfaction is "a psychological state resulting from a process of emotional and cognitive evaluation (Oliver, 1981). Oliver (1980) showed that satisfaction has an indirect effect on the intentions of customers around the attitude after the purchase. Bearden and Teel (1983) also found a similar result in services. Fornell and al. (1996) show that cumulative satisfaction is an important antecedent of loyalty shown by the intention of repurchases and tolerance of a price increase. Cronin and Taylor (1992), in turn, showed that satisfaction has a significant effect on purchase intentions. Taylor and Baker (1994) showed that the perceived quality and satisfaction have a joint influence on purchase intentions. Their results imply that the intention is strongly expressed when the service is excellent and the customer is satisfied. Finally, improving the satisfaction can decrease the sensitivity of customers regarding the price increase by the company or lower prices by competitors.

\section{IV- The influence of perceived quality on satisfaction}

About the virtual environment, the research that has addressed this relationship are limited. We can even identify four studies: Wolfinbarger and Gilly (2003), Rolland (2003), Bressolles (2004) and Rodgers and al. (2005). Rolland (2003) studied the relationship between the perceived quality of a website (Fnac.com) and satisfaction with the site.

The results shows that the perceived quality of the site influence positively satisfaction (for site information model, the regression coefficient is 0.792, $\mathrm{p}=0.000$ and for model website procurement, it is $0.808, \mathrm{p}=0.000)$. This relationship has been demonstrated by Wolfinbarger and Gilly (2003) they shown that the overall quality of service, predicts strongly satisfaction of users $\left(\mathrm{R}^{2}=0.70, \mathrm{p}=0.001\right)$. The same result was also confirmed by Bressolles (2004) who studied this link in a shopping experience at two sites: a site for digital products (Nomatica) and a travel site (Nouvelles Frontières). The results show a strong and positive relationship between the two concepts $(\gamma=0.927$ for the global model and the two sites studied: $\gamma=0.855$ for Nouvelles Frontières and $\gamma=0.953$ for Nomatica. It follows that service quality influence positively satisfaction after a purchase from a merchant site. 
Testing this relationship on a sample of students ( $\mathrm{N}=836)$, Rodgers and al. (2005) showed that the perceived quality exerted a positive influence on satisfaction online $(\gamma=$ $0.20, \mathrm{p}<0.05)$. This relationship is stronger when respondents have higher online experience $(\gamma=0.36, p<0.01)$. Instead, if the online experience is weak, this relationship is negative $(\gamma=-0.47)$, which means that it is less likely to satisfy consumers with less online experience even less providing good quality service.

Wang (2003, p.2) notes that traditionally, the level of satisfaction is determined, among other things, the quality of service. Therefore, the level of e-satisfaction is also determined by the quality of e-services. In this research, the perceived quality of Internet banking is defined as "the degree to which Internet banking facilitates the management of banking services effectively and efficiently" (adapted from Zeithaml and al. 2000). Satisfaction is conceptualized as an overall assessment of the consumer experience. We consider the concepts of "perceived quality and satisfaction in a relational perspective that is to say, as feedback from a cluster of experiences (Aurier and Evrard, 1998). We also assume that the perceived quality is an antecedent of satisfaction in the physical environment. If this result is supported by an abundant literature in this context, few studies have addressed in the virtual realm where we are. Our goal is to test this relationship in the context of Internet banking. For this, we hypothesize the following:

$\mathrm{H}$ 1: The perceived quality of Internet banking influence positively the overall satisfaction of consumer

\section{V- The influence of satisfaction on commitment}

Satisfaction as a predictor of commitment is a result well defended in several studies. Chiou (2004), examining the antecedents of commitment to a supplier of Internet access, showed that overall satisfaction of consumers with regard to a provider of Internet access influence positively their commitment to the respect of that supplier $(\gamma=0.37, t=2.84, p$ $<0.05)$. Satisfied consumers are more likely to use the same website in the future, to resist the face of competing alternatives and to generate positive word of mouth. Also, Allagui and Temessek (2004) showed that most consumers are satisfied with their experience with a provider of e-services, it would be more committed to it and its intentions to return and re-purchase will be. Results from the structural modeling confirm a direct and positive influence of e-satisfaction on commitment $(\gamma=$
0.89, $\mathrm{t}=12.97)$. The authors conclude that satisfaction with a site (portal site Yahoo) is an important antecedent of commitment.

They add that more site evaluation will be positive more the surfer manifested its intention to revisit the site and using its services in the future. Park and Kim (2003), examining the influence of satisfaction with information available on the site and relational benefits on commitment to the site, show that satisfaction explains a strong commitment to the regard the site $(\beta=0.448, t=12,469, p$ $<0.001$ ). The authors emphasize the important role of satisfaction in the formation of consumer engagement in the context of buying books online. Bansal and al. (2004) studied the antecedents and consequences of online satisfaction from customers of 145 companies mainly "multi-channel distribution of products / services online, their results show the existence of a significant and positive relationship between the e-overall satisfaction and intention to re-purchase $\left(\mathrm{R}^{2}=0.38, \beta=\right.$ $0.61, t=6.78)$. Anderson and Srinivasan (2003) also showed on a sample of 1211 online consumers, that satisfaction has a positive and significant impact on intention $(\beta=0.28, \mathrm{t}=$ 5.143). Rodgers and al. (2005) confirm this result and add that the link is stronger for consumers who have a great online experience than consumers less experienced. Given this research, overall satisfaction is presumed to be the natural predictor of commitment. Therefore, it is reasonable to predict that consumers who are satisfied with Internet banking to make greater reuse. We therefore postulate that:

H 2: The overall consumer satisfaction with Internet banking influence positively commitment.

\section{VI-The mediating role of satisfaction on the relationship between perceived quality and commitment}

Through our literature review, we have shown the influence of perceived quality on satisfaction of a hand, and the influence of satisfaction on commitment, on the other. It is therefore plausible to consider the mediating role of satisfaction in the relationship between perceived quality and commitment. This relationship has been demonstrated by Sabadie (2001) in a context of public services. The author has shown that satisfaction mediate the effect of perceived quality on commitment (model citizen and legal). The results show that the predictive power of perceived quality on commitment is higher when mediated by satisfaction. It follows that the performances of public service influence positively user's 
satisfaction, which in turn influence positively their commitment. This causal chain perceived quality-satisfaction-commitment validated in the context of traditional services should be considered in the context of electronic services. The following hypothesis is formulated:

$\mathrm{H}$ 3: Satisfaction is a variable mediating the influence of the perceived quality of Internet banking on the commitment.

\section{VII - Research Methodology}

For a good relevance of our results, three data collections were made. The first was conducted using an online survey. A convenience sample of 203 users of Internet Banking has been established. It comprises $42.4 \%$ men and $57.6 \%$ women. In addition, $92.2 \%$ of respondents use the website to manage their bank accounts in the last 2 years (access to balances, transfers online simulations appropriations request for advice, research information ....). For the second collects a new sample of convenience was made: 272 questionnaires. The sample is composed of $35.7 \%$ men and $64.3 \%$ women. $89.7 \%$ have a high level of education. $85.7 \%$ use the Internet every day or almost over 2 years. More than half $(57.7 \%)$ respondents use the sites of their banks several times a week to manage their banking activities. The conditions of the third collection remain the same as previous. The method of collecting survey data online has been retained because of its efficiency and speed responses. The composition of his sample is not too distant from the second collection

\section{VIII- Selection and validation of scales}

Measuring the perceived quality of Internet banking has been developed for this research. The procedure for construction of this scale has followed the recommendations of the paradigm of Churchill (1979). The eight steps in the exploratory and confirmatory phases of this paradigm have been met. The purification process relies on two exploratory analysis (n1 = $203 \mathrm{n} 2=272$ ) and confirmatory factor analysis ( $\mathrm{n}=629$ ). The scale created comprising 21 items measuring 7 dimensions of perceived quality of Internet banking. The 7 dimensions chosen are: the design of the site, the ease of use, the privacy, the information quality, the financial security, the gain of time and interactivity. To measure satisfaction, we chose to assess the cumulative satisfaction as overall assessment from a set of experiments. For this, the scale of Aurier and Evrard (1998) enriched by Sabadie (2001) and context-specific Web sites by Rolland (2003) was chosen. To measure the commitment to a website, the scale developed by Park and Kim (2003) and validated by Allagui and Temessek (2004), was selected.

The validity of measures of variables: perceived quality, satisfaction and commitment, has been verified. The psychometric qualities of these scales have been verified through two exploratory factor analysis ( $\mathrm{n} 1=203 \mathrm{n} 2=272)$ supported by a confirmatory factor analysis (n $=629$ ). The scale of perceived quality retains its structure of 7 dimensions. The scale of satisfaction has not been validated so a singleitem scale of satisfaction was chosen for further analysis. The scale of commitment has been validated and consists of 3 items instead of 4 of departure.

\section{IX- Results and discussions}

Before testing hypotheses, testing the conceptual model has been conducted to verify the quality of its fit to empirical data. Different index show that the model is acceptable and present good fit with empirical data for that parameter estimates are reliable. The $\chi^{2}$ adjusted degree of freedom is equal to 5.07 , the CFI, NFI and NNFI are respectively 0.932, 0.917 and 0.909 , the RMSEA is equal to 0.081 with an interval of $(0.070,0.092)$, the AIC is equal to 125.94 much lower than the independent model (2409.17). So the model fit is acceptable and the interpretation of different assumptions can be made. The estimation of structural parameters of the model show the existence of a significant and positive relationship between perceived quality and satisfaction $(\gamma=0.769$ and $\mathrm{T}=14,417)$. This relationship is well demonstrated in the traditional literature course, but its replication in the context of Internet banking is a highly original contribution of this research. Thus, the perceived quality by users of Internet banking affects positively their satisfaction. The hypothesis $\mathrm{H} 1$ is confirmed. The regression coefficient of satisfaction on commitment has a positive and significant $(\gamma=0.225$ and $\mathrm{T}=$ $2,415)$. Thus, the satisfactions of the surfer influence positively its commitment to the Internet banking. The hypothesis $\mathrm{H} 2$ is validated.

The results also show that the predictive power of perceived quality on commitment is lower when it is mediated by satisfaction $(0.029$ $<0.779$ ). Therefore, the mediating role of satisfaction on the relationship between perceived quality and commitment is not established. Hypothesis H3 is not validated. We present in Figure 1, the relationship model of the perceived quality of Internet banking with their values of standardized regression coefficients. 


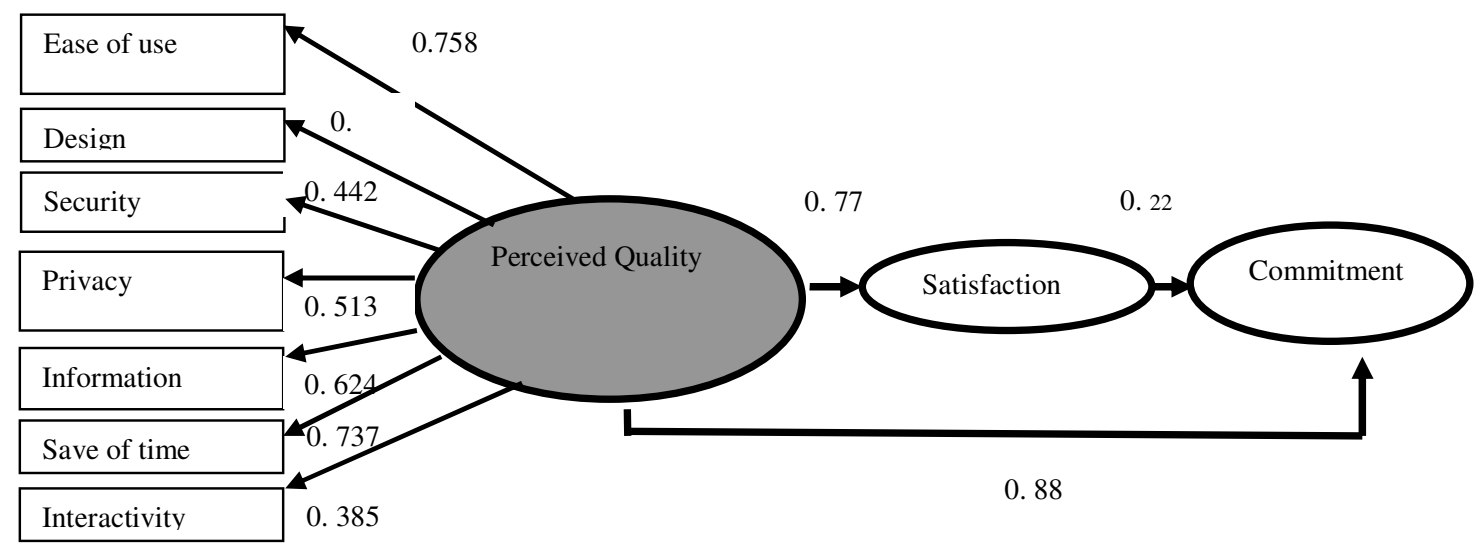

Figure 1: Standardized regression coefficients of SEM model of the perceived quality of Internet Banking

satisfied customers are more prone to use the same website in the future and resist to the face

We assumed that the perceived quality influence positively the overall satisfaction of users of the Internet banking. The research results show a significant positive relationship between perceived quality and satisfaction. Satisfaction is largely determined by the perceived quality as evidenced by its regression coefficient $(\gamma=0.77)$. The influence of perceived quality on satisfaction was confirmed with a very strong bond but validation of this relationship is not a surprise because several researches developed in the traditional services (Cronin and Taylor, 1992; Spreng and mackoy, 1996; Sabadie, 2001; Champitaz and Swaen, 2004) and Internet (Wang, 2003; Wolfinbarger and Gilly, 2003; Rolland, 2003; Bressolles, 2004 and Rodgers and al. 2005) have all shown that. Our contribution is therefore the validation of this relationship in the context of Internet Banking with a coefficient of $\gamma=0.77$. In our context, the perceived quality can strongly predict the satisfaction of users of the Internet banking. The performances of Internet Banking on the facets of the perceived quality contribute to explaining $60 \%$ of user satisfaction with Internet banking.

Overall satisfaction was assumed in this research as an antecedent of commitment. Our results showed a significant and positive influence of satisfaction on commitment $(\gamma=$ $0.22, \mathrm{t}=2415, \mathrm{p}<0.05$ ).

The consumers satisfied with Internet banking are prompt to make greater reuse of Internet Banking in the future and to

visit their bank website first if needed banking services. These results are consistent with the results of Park and Kim (2003), Bansal and al. (2004) and Chiou (2004) who have shown that of competing alternatives. More consumers are satisfied with their experiences with electronic services, the more they are committed to them and their intentions to return and re-purchase will be. Furthermore, validation of this hypothesis means that the consumer undertakes to a website or online service should be especially pleased by it.

In the context of Internet banking, the results indicate that satisfaction does not mediate the influence of perceived quality on commitment. The predictive power of perceived quality on commitment is less when it is mediated by satisfaction. The causal chain perceived quality $\rightarrow$ satisfaction $\rightarrow$ commitment is not validated. The perceived quality directly influences the commitment of users to Internet banking. The strength of this direct link is very high (0.88). This result is consistent with that found by Sabadie (2001) who has shown that satisfaction does not mediate the effect of the model of customer perceived quality on the commitment in the context of a public service (Regional Express Transport ). Validation in the context of an online transaction service is an important result. It is also interesting to note that customer satisfaction is less critical than the perceived quality in relation to client commitment ( $y=0.22$ against 0.88 ). A possible explanation for this result could be that most customers do business with their bank websites when they are of good quality even if they are not completely satisfied.

\section{X- Research Contributions}

From a theoretical viewpoint, this search continues the few works that have explored the concept of perceived quality of online services on one hand. On the other hand, it enriches the theoretical framework to account for the specificity of Internet Banking. Another theoretical contribution of this research is 
studying the influence of perceived quality on satisfaction and the influence of satisfaction on commitment to Internet banking. The mediating role of satisfaction on the relationship between perceived quality and commitment has also been examined. On the managerial level, the results of this research show that satisfaction with Internet banking contributes to the commitment of customers to use Internet Banking, visit the bank website in the first place if necessary banking and to maintain their relationships with their banks website. Thus, bankers should be aware of the importance of promoting factors of satisfaction because it is a strategy that could produce favourable behavioural intentions among customers.

\section{XI- Research limitations}

Like any study belonging to the social sciences, this study has limitations:

\section{Limitations inherent in the external validity of results:}

The application of our research to one sector represents the main achievement to external validity. This limit could be eased by a few appropriate remarks on the study area. Research has so far given little or no attention to the study of Internet banking. This research is, to our knowledge the first study on the perceived quality of Internet banking. In addition, the banking sector has traditionally been very receptive to the research because of its extreme sensitivity for improving customer service. Therefore, the interest of the subject allows us to conclude that this limit is of less importance. The second limitation relates to the convenience sample "student". While students are a more homogeneous sample and represent a better target for our subject. However, they are still individual consumers, not least because they face tighter budgetary constraints.

\section{Limitations inherent in the internal validity of results:}

The instrumentation effects and external sources of variance are the main threats to internal validity of our results

Instrumentation effect: this effect is the impact of a bad instrument or misapplication of a technical investigation on the collection of observations and results. To minimize this bias, particular attention was given to the development and selection of measuring instruments used in this research. The questionnaire was also designed with attention and has been the subject of two pre-tests and multiple consultations with experts and academic researchers prior to collection from our target. The potential effect of this bias has been limited thanks to the online survey that enabled us to respond quickly and in real time to make changes or clarification to respondents.

The sources of uncontrolled variance: They can come from two sources:

The performance of the hardware of the user: the fact that the respondent has a broadbet connection can change its opinion on the effectiveness of the website and therefore on some dimensions of perceived quality including ease of use.

The date of last visit: the perception could be changed over time. This source of bias does not arise in our case since the descriptive statistics performed on our sample show that the frequency of visiting the bank website varies between one and seven days.

\section{Annexe 1: the perceived quality of Internet banking dimensions}

\begin{tabular}{|c|c|}
\hline Dimensions & Definitions \\
\hline Design of the site & the ability to interface to reassure the customer and the personify the bank \\
\hline Ease of use & corresponds to the capacity of the bank website to be simple and easy to use \\
\hline Financial security & $\begin{array}{l}\text { refers to the fact that the customer perceives that his bank informations are } \\
\text { secure and that nobody can access their accounts }\end{array}$ \\
\hline Interactivity & $\begin{array}{l}\text { vise la facilité du dialogue avec la banque via le site } \\
\text { the ease of dialogue with the bank via the website }\end{array}$ \\
\hline Information quality & $\begin{array}{l}\text { the degree to which the bank website can learn about its accounts and other } \\
\text { products and services of the bank }\end{array}$ \\
\hline Privacy & $\begin{array}{l}\text { the degree to which the customer perceives that his personal informations are } \\
\text { protected }\end{array}$ \\
\hline Save time & $\begin{array}{l}\text { corresponds to the time savings provided by the implementation of Internet } \\
\text { Banking }\end{array}$ \\
\hline
\end{tabular}


Annexe 2: variables measurement

\section{Table 1: Perceived quality of Internet banking scale}

\begin{tabular}{|l|}
\hline Design \\
\hline The site of my bank is visually pleasing \\
\hline The site of my bank is visually attractive \\
\hline The colours of my bank website are well prepared \\
Privacy \\
My bank website protects banking secrecy \\
I think my privacy is protected on my bank website \\
I trust the site of my bank use not my personal information \\
inappropriately \\
I trust the security of my bank website \\
Information quality \\
My bank website meets my information needs \\
The information on my bank website is relevant \\
The information corresponds to what I need \\
Financial security \\
My bank communicates its security policies on its website \\
On my bank website, there are clear explanations of \\
security \\
Save time \\
It's quick to make transactions on my bank website \\
I earn a lot of time using my bank website \\
The site of my bank does not make me lose my time \\
Interactivity \\
The site provides ways to contact an advisor at my bank \\
I can communicate with someone from my bank (by e- \\
mail.) if I have problems with my account \\
\hline
\end{tabular}

\section{Table 2: Commitment scale}

- I will not stop using my bank website in the future

- I will continue to use the services of my bank website

- I will visit my bank website first if i need banking

\section{Table 3: Overall satisfaction Scale}

Finally, with your bank website you are:

\begin{tabular}{|c|l|c|c|c|c|c|}
\hline Extremely & Very & Dissatisfied & $\begin{array}{l}\text { Neither } \\
\text { satisfied } \\
\text { nor } \\
\text { dissatisfied }\end{array}$ & Satisfied & $\begin{array}{l}\text { Very } \\
\text { Satisfied }\end{array}$ & $\begin{array}{l}\text { Extremely } \\
\text { Satisfied }\end{array}$ \\
\hline 1 & 2 & 3 & 4 & 5 & 6 & 7 \\
\hline
\end{tabular}

\section{References}

Aladwani A.M. (2001), Online banking: a field study of driver, development challenges, and expectations; International Journal of Information Management. 21; pp. 213-225.

Allagui A. and Temessek, A. (2004, The loyalty of users of an Internet portal services: Proposal and Test of a model integrator, C.R.G.N.A), IAE of Nantes, French.
Aurier P. and Evrard Y. (1998), Development and validation of a scale for measuring consumer satisfaction, Proceedings of the $14^{\text {th }}$ International Congrès of FMA,.Bordeaux, French

Bansal H.S., McDougall G., Dikolli S.S. and Sedatole K.L. (2004), Relating e-satisfaction to Behavioral outcomes: an empirical study, Journal of Services Marketing, vol.18, 4.

Bateson, J.E.G., Self-Service Consumer: An Exploratory Study, Journal of Retailing (1985), 61, 3, pp. 49- 76. 
Boulaire C. and Mathieu, A. (2000), Loyalty to a website: proposal of a preliminary conceptual framework, Proceedings of the $16^{\text {th }}$ International Congress of the FMA, Montréal. Bressolles G. (2004), The quality of electronic service, NETQUAL: scale, consequences and moderating variables, Ph.D. in Management Sciences, University of Toulouse I.

Champitaz R. and Swaen, V., The perceived quality as a determinant of customer satisfaction in business-to-business. An empirical study in the field of telephony, Research and Application in Marketing (2004), vol. 19,2 , pp. 31-52.

Chiou J.S.(2004), The antecedent of consumers' loyalty toward Internet Service Providers, Information \& Managemen), vol. 41, pp. 685695.

Churchill G.A. (1979), A Paradigm for Developing Better Measures of Marketing Constructs, Journal of Marketing Research, Février, 16, 64-73.

Cronin J.J.Jr. and Taylor S.A. (1992), Measuring service quality: A reexamination and extension, Journal of Marketing, 56;

Jayawardhena C. (2004), Measurement of Service Quality in Internet banking: The Development of an Instrument, Journal of Marketing Management,vol. 20, 185-207.

Jun M. and Cai S. (2001), The key determinants of Internet bancaire service quality: content analysis, The International Journal of Bank Marketing ,vol.19, 7.

Liao Z. and Cheung M.T. (2002), Internet based e-banking and consumer attitudes: An empirical study, Information and Management vol. 39, pp. 283-295.

Liu C. and Arnett K.P. (2000), Exploring the factors associated with Web site success in the context of electronic commerce, Information \& Management, vol. 38, 1.

Llosa S. (1996), Contribution to the study of satisfaction in services, $\mathrm{PhD}$ in Management Sciences, University of Aix Marseille III

Meuter M.L., Ostrom A.L. (2000), Roundtree R.I. and Bitner M.J., Self-service technologies: Understanding customer satisfaction with technology-based service encounters, Journal of Marketing, 64, 3, 50-64.

Novak, T.P., Hoffman, D.L. and Yung Y.F. (2000), Measuring the Customer Experience in Online
Environments: A Structural Modeling Approach, Marketing Science,vol. 19,1.

Park C.H. and Kim Y.G. (2003), Identifying key factors affecting consumer purchase behavior in an online shopping context, International Journal of Retail \& Distribution Managemnt vol. 31,1 , pp. 16-29.

Rodgers W., Negash S. and Suk K. (2005), The Moderating Effect of On-line Experience on the Antecedents and Consequences of On-line Satisfaction, Psychology \& Marketing, vol. 22, 4, pp. 313-331.

Rolland S. (2003), The impact of Internet use on perceived quality and consumer satisfaction, $\mathrm{PhD}$ in Management Sciences, University Paris Dauphine.

Roussel P., Durrieu F. (2002), Campoy E. and El Akremi A.,Methods of structural equations: Research and Management Applications, Ed. Economica.

Sabadie W. (2001), Contribution to the measuremnt of the perceived quality of public services, PhD in Management Sciences, University of Toulouse 1.

Santos J., E-service quality: a model of virtuel service quality dimensions, Management Service Quality (2003), vol.13,

Srinivasan S.S. (2002), anderson R. and Ponnavolu K., Customer loyalty in e-commerce: an exploration of its antecedents and consequences, Journal of Retailing, 78, pp.4150.

Szymanski D.M. and Hise R.T., E-Satisfaction: An Initial Examination, Journal of Retailing (2000), 76 (3), 309.

Wang M. (2003), Assessment of E-Service Quality via E-Satisfaction in E-Commerce Globalisation, The Electronic Journal of Information Systems in Developing Countries,11,10, p.1-4.

Wolfinbarger M. and Gilly M.C. (2003), E-TailQ: dimensionalizing, measuring and predicting retail quality, Journal of Retailing, 79, 183-198.

Yoo B. and Donthu N. (2001), Developing a Scale to Measure the Perceived Quality of Internet Shopping Sites, Quarterly Journal of Electronic Commerce, 2,1, 31-47.

Zeithaml V. A., Parasuraman A. and Malhotra A. (2000), E-service quality: definition dimensions and conceptuel model, Working paper, Marketing Science Institute Cambridge, MA. 